\title{
Cataract surgery performed before 800 B.C.
}

\author{
P. N. ROY, K. S. MEHRA, AND P. J. DESHPANDE* \\ Department of Ophthalmology and ${ }^{*}$ Department of Shalya Shalakya, Institute of Medical Sciences, Banaras Hindu \\ University, India
}

Duke-Elder (1969) pointed out that cataract surgery was performed in India by Sushruta by the couching technique long before the Christian era. Sushruta's method, which is described in detail in "Sushruta Samhita, Uttar Tantra", appears to the modern reader to be more akin to extracapsular lens extraction than to couching.

The medical treatise "Sushruta Samhita" was written in verse in Sanskrit approximately 800 years before the birth of Christ. An examination of the relevant verses in their original language discloses the following points concerning the treatment of cataract.

\section{Preoperative care}

The patient was recommended to have an oily massage followed by a kind of heat-bath.

\section{Operative technique}

The patient was asked to sit on a high stool, with the surgeon stitting in front of him face to face. He was instructed to look at the surgeon's nose while the operator placed the tip of his little finger on the bony margin of the outer angle of the orbit, holding a sharp-pointed needle ( Yav Vakra Shalaka) between his thumb, index, and middle finger. The point entered the anterior chamber, at the junction of the medial and lateral two-thirds of the outer portion of the white layer (sclera) of the eye ball. If a sound

Address for reprints: Dr. K. S. Mehra, 4 Medical Enclave, Banaras Hindu University, Varanasi-221005, India was produced followed by the gushing of watery fluid, then the surgeon's needle was considered to be in the correct part of the eye ball, but if this puncture was followed by bleeding, it meant that it was misplaced. Care was taken to avoid blood vessels present in that region.

The tip of the needle was then made to incise the capsule of the lens. With the needle in this position, the patient was asked to blow down the nostril, while closing the opposite nares. After this procedure, according to Sushruta, lens material came out alongside the needle and when the patient was able to perceive objects, the needle was removed.

\section{Postoperative care}

A few indigenous medicines (roots and leaves) were applied to the eye, with a bandage. The patient was then instructed to lie flat on his back and avoid any movement, particularly sneezing and coughing. The operated eye was examined daily until the tenth day. If the whitish mass appeared again in the pupillary area the same procedure had to be repeated.

\section{Summary}

The general belief that the technique of cataract extraction in India in the Sushruta period (800 B.c.) was couching is no longer tenable. A study of the original text suggests that the method was more closely allied to the extracapsular extraction of recent times.

\section{Bibliography}

DUKE-ELDER, S. (1969) “System of Ophthalmology", vol. i I, p. 249. Kimpton, London

"Sushruta Samhita-Uttar Tantra", chap. I 7, verses 57-70 